\title{
Detection of Extended Spectrum $\beta$-Lactamases (ESBL) Producing Bacteria in Sepsis Suspected Neonates
}

\author{
Sabita Nepal,, Sushma Koirala,, ${ }^{1}$ Subash Thakur, ${ }^{2}$ Susmita Bhattarai,, ${ }^{3}$ Suraj Dhungana, ${ }^{3}$ \\ Sharad Giri, ${ }^{4}$ Santosh Khanal ${ }^{5}$ \\ ${ }^{1}$ Department of Microbiology, National College, Khusibu, Kathmandu, Nepal; \\ ${ }^{2}$ Department of Microbiology, Paropakar Maternity and Women's Hospital, Thapathali, Kathmandu, Nepal; \\ ${ }^{3}$ Nepal Institute of Health Sciences, Jorpati, Kathmandu, Nepal; \\ ${ }^{4}$ Vinayak Collage of Health Science, Batisputali, Kathmandu, Nepal; \\ ${ }^{5}$ Department of Microbiology, Tri-Chandra Multiple Campus, National College, Ghantaghar, Kathmandu, Nepal.
}

\begin{abstract}
Introduction: Neonatal sepsis is a clinical syndrome which is caused when blood stream of infant is invaded by the bacteria in first month after birth.

Objective: The objective of the study was to identify bacteria involved in the infection and to determine "extended spectrum beta-lactamase" (ESBL) producing bacteria from blood samples of sepsis suspected neonates in Neonatal Intensive Care Unit and Special Care Baby Unit.

Methods: This cross-sectional study was conducted from January to July 2019 at Microbiology laboratory of Paropakar Maternity and Women's Hospital. A total of 380 venous blood specimens were included in the study. The blood culture was performed and organisms were identified with standard microbiological methods. The Antibiotic susceptibility test was performed using modified Kirby Bauer disk diffusion method. Screening of the organisms was done using cefotaxime and ceftazidime antibiotic disc and confirmation of ESBL was done by combined disk test. The data were considered statistically significant if p-value was $<0.05$.
\end{abstract}

Results: Out of a total of 380 blood specimens, the prevalence of neonatal sepsis was found to be $21.05 \%$ among which $57.5 \%$ were EOS type and $42.5 \%$ were LOS type. In EOS, E. coli (72.73\%) was the predominant isolate while CoNS (100\%) was the predominant isolate in LOS. Of the total 80 isolates, $65 \%$ isolates were found multidrug-resistant (MDR) whereas $58.75 \%$ of isolates were found to be ESBL producers.

Conclusions: This study concludes that routine bacterial surveillance and study of their resistance patterns is an essential component of neonatal care unit

Keywords: Extended spectrum $\boldsymbol{\beta}$-Lactamases; neonates; neonate intensive care unit; special care baby unit; sepsis.

\section{INTRODUCTION}

Sepsis is a deregulated response to infection that may accompany to organ failure, responsible for

\footnotetext{
Correspondence

Mr. Santosh Khanal

Email : santosh.khanal@trc.tu.edu.np

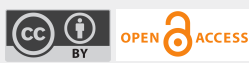

Citation

Nepal S, Koirala S, Thakur S, Bhattarai S, Dhungana S, Giri S, Khanal S. Detection of Extended Spectrum $\beta$-Lactamases (ESBL) Producing Bacteria in Sepsis Suspected Neonates. Nepal J Health Sci. 2021 Jul-Dec; 1(2):7-14.
}

sixth leading cause of neonatal death within 28 days and the eighth leading cause of infant's death within first year of life. ${ }^{1}$ Neonatal sepsis is a bloodstream infection occurring in infants within 28 days of birth and is one of the major causes of neonatal morbidity and mortality each year. ${ }^{2}$ Gram negative bacteria are the major cause of neonatal sepsis in developing countries whereas Group B Streptococcus is the major cause of neonatal sepsis in developed countries. ${ }^{3}$ On the basis of infant's age during onset of symptoms, neonatal sepsis is divided into two types: Early-onset sepsis that occur within first 72 
hours of birth and late-onset sepsis that occur after 72 hours of birth. ${ }^{4}$

In Asia, the study has reported the incidence of neonatal sepsis of 7-38 in every 1000 live birth. ${ }^{3}$ However, in Nepal, limited information is available about extended spectrum beta lactamase (ESBL) producing bacterial isolates in neonates. Thus, the present study was carried out to identify ESBLproducing bacteria isolated from neonatal sepsis in a tertiary care hospital in Nepal.

\section{METHODS}

The cross-sectional study was conducted from January to July 2019 at Microbiology laboratory of Paropakar Maternity and Women's Hospital. All neonates who were suspected with neonatal sepsis, admitted to Neonatal Intensive Care Unit (NICU) and Special Care Baby Unit (SCBU) were included in the study. Patients were selected on the basis of clinical decision of sign and symptoms of sepsis at the time of admission or during their hospital stay. Those patients whose parents refused to be part of the study and those who were already on antibiotics therapy after sepsis were excluded from the study.

Total number of 380 estimated blood samples was included as a sample for the study which was calculated using a single proportion formula ${ }^{5}$ keeping 95\% confidence level and 5\% confidence interval. The blood samples were collected by a well-trained nurse and Pediatrician by using aseptic technique. The total of $0.5-1 \mathrm{ml}$ venous blood was drawn from the antecubital vein. The blood was then inoculated into Brain Heart Infusion Broth and the blood culture bottle was transported to the Microbiology Laboratory of Paropakar Maternity and Women's Hospital for the culture and antibiotics susceptibility tests. All blood culture bottles were incubated aerobically at $37^{\circ} \mathrm{C}$ and were observed daily for up to 5 days for perceptible microbial growth by observing any one of the following: coagulation of broth, turbidity, hemolysis and gas production. Since growth on only one bottle is considered as contaminant, blood was inoculated on two aerobic culture bottles from every single patient and growth on both bottles were considered as pathogen. That blood culture bottle with signs of microbial growth was subcultured onto Blood Agar (BA), Chocolate Agar (CA) and MacConkey Agar (MA).

The MA and BA agar plates were incubated in aerobic condition and $\mathrm{CA}$ in the micro-aerophilic atmosphere using a candle jar at $37^{\circ} \mathrm{C}$ for $24-48$ hours. The observation was repeated until 7 days before discarding the blood culture bottle where growth was not observed and declaring them to be microorganism free after getting the result of routine subculture on BA, MA, and CA as no growth. All positive blood cultures were further sub-cultured on Nutrient agar (NA) and were incubated at $37^{\circ} \mathrm{C}$ for 24 hours so as to obtain pure bacterial colonies. Isolated bacteria were identified by their morphological characteristic on the media, Gram staining reaction and confirmed by different biochemical reactions. As per the recommendation of Clinical and Laboratory Standards Institute ${ }^{6}$, the antibiotic susceptibility testing was performed using Modified Kirby-Bauer Disk Diffusion Method. A suspension was made by inoculating 3-4 pure bacterial colonies into the nutrient broth. Before distributing the suspension on the surface of Muller Hinton agar, the turbidity was matched with $0.5 \mathrm{McF}$ arland standards.

After the turbidity was matched, the suspension was inoculated on MHA and the plates were left at room temperature for 5-10 minutes to dry and 5 antibiotic discs were incorporated on each $90 \mathrm{~mm}$ MHA plate. The antibiotics discs used during the test were Ciprofloxacin (CIP) $(5 \mu \mathrm{g})$, Cotrimoxazole (COT) (30 $\mu \mathrm{g})$, Piperacillin/tazobactam (PIT) $(10 \mu \mathrm{g})$, Amikacin (AK) $(30 \mu \mathrm{g})$, Gentamicin (GEN) $(10 \mu \mathrm{g})$,

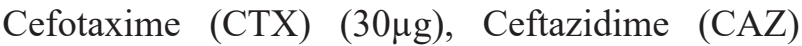
$(30 \mu \mathrm{g})$, Erythromycin (E), Meropenem (MRP) $(10 \mu \mathrm{g})$, Vancomycin (VA) $(5 \mu \mathrm{g}),(15 \mu \mathrm{g})$, Oxacillin $(\mathrm{OX})(10 \mu \mathrm{g})$. The plate was incubated at $37^{\circ} \mathrm{C}$ for 24 hours. Diameters of the zone of inhibition of the incorporated discs were measured according to the CLSI (2018) and reported to be resistant, intermediate and sensitive. 
Bacteria which were resistant to three or more than three antimicrobial classes were considered as Multidrug resistant bacteria. ${ }^{7}$ If bacteria were resistant to any of Ceftazidime and Cefotaxime disc with zone of inhibition $\leq 22 \mathrm{~mm}$ for ceftazidime and $\leq 27 \mathrm{~mm}$ for cefotaxime, then they were suspected as ESBL producer and were confirmed by combined disc test using Cefotaxime- clavulanate and Ceftazidimeclavulanate as per recommendation of CLSI guideline $2017 .{ }^{7} \mathrm{~A}$ positive ESBL test was confirmed when the zone of inhibition was greater than or equal to $5 \mathrm{~mm}$ around combined disk (Cefotaximeclavulanate or Ceftazidime- clavulanate) than single disk (Cefotaxime or Ceftazidime).

The quality control procedures of the standard medical microbiology laboratory were strictly applied during the collection, transport and processing of the specimens for standard results. The adequate control of all equipment and material was done during the research. Each agar, biochemical reagents and antibiotic disks were checked for their respective manufacture date, expiry date, lot number and for appropriate storage condition. Five percentages of media were incubated at $37^{\circ} \mathrm{C}$ for 24 hours from each and every batch of the prepared media to ensure the purity of the culture media. The purity plate was used to ensure that the colony used for biochemical tests was pure. The inoculum density of bacterial suspension during AST test was standardized by comparing it to $0.5 \mathrm{McF}$ arland standards. The quality of the AST test was ensured by maintaining the thickness of MHA at $4 \mathrm{~mm}$ and $\mathrm{pH}$ at 7.2-7.4. Double data entry method was used to ensure the accuracy of data.

All the data were entered and analyzed using Statistical Package of Social Science (SPSS) software version 16 and the inferential statistics such as Chi-square test was used to find the association between the variables at $95 \%$ confidence level (p-value $<0.05)$

The ethical approval was obtained from Institutional Review Committee of Paropakar Maternity and Women's Hospital's development Board (Ref number 59-11-1874). The permission to conduct the research was obtained from director of the hospital. Consent was taken from the parents to include neonates on the study. Demographic, clinical and other relevant data were obtained by pediatrician/s for the study. The study was conducted as per the ethical regulations and principles of the Institutional Review Committee of Paropakar Maternity and Women's Hospital Women's Hospital.

\section{RESULTS}

Figure 1 demonstrates that of 380 blood samples, 80 blood culture specimens were positive. Among blood culture positive, $43(53.75 \%)$ were from males and $37(46.25 \%)$ were from females. The prevalence rate of neonatal sepsis was found to be $21.05 \%$.



Figure 1: Bacterial growth pattern among the patients. 
Neonatal sepsis was divided into two different categories on the basis of days of birth as early onset sepsis (EOS) and late onset sepsis (LOS) of neonates. Out of 80 blood culture positive samples, 46 (57.5\%) were EOS type and $34(42.5 \%)$ were LOS type. In EOS, E. coli $(72.73 \%)$ was predominant isolate followed by $K$. oxytoca $(71.43 \%)$ and Acinetobacter spp. (68.75\%). CoNS (100\%) were also predominant isolate in LOS followed by $S$. aureus (85.71\%). There was significant association between isolated organisms and types of neonatal sepsis (Table1).

Table 1: Bacteriological profiles of early - onset sepsis (EOS) and late - onset sepsis (LOS).

\begin{tabular}{|l|c|c|c|c|}
\multicolumn{1}{|c|}{ Organisms } & EOS & LOS & Total & p-value \\
\hline E. coli & $\mathbf{N}(\mathbf{\%})$ & $\mathbf{N}(\mathbf{\%})$ & $\mathbf{N}$ & \\
\hline K. pneumoniae & $8(72.73)$ & $3(27.27)$ & 11 & \\
\hline K. oxytoca & $18(60)$ & $12(40)$ & 30 & \\
\hline Acinetobacter spp. & $5(71.43)$ & $2(28.57)$ & 7 & \\
\hline Enterobacter spp. & $11(68.75)$ & $5(31.25)$ & 16 & 0.001 \\
\hline Citrobacter spp. & $2(33.33)$ & $4(66.67)$ & 6 & \\
\hline S. aureus & $1(50)$ & $1(50)$ & 2 & \\
\hline CoNS & $1(14.25)$ & $6(85.71)$ & 7 & \\
\hline Total & 0 & $1(100)$ & 1 & \\
\hline & $46(57.5)$ & $34(42.5)$ & $80(100)$ & \\
\hline
\end{tabular}

Table 2: Antibiotic resistant pattern of isolated organisms.

\begin{tabular}{|c|c|c|c|c|c|c|c|c|}
\hline $\begin{array}{l}\text { Organisms } \\
\text { Antibiotics }\end{array}$ & $\begin{array}{c}\mathrm{K} . \\
\text { Pneumoniae } \\
\mathrm{n}=\mathbf{3 0}\end{array}$ & $\begin{array}{c}E . \text { coli } \\
\mathrm{n}=11\end{array}$ & $\begin{array}{c}\text { Acinetobacter } \\
\text { spp. } \\
\mathrm{n}=16\end{array}$ & $\begin{array}{c}\text { K. oxytoca } \\
\mathrm{n}=7\end{array}$ & \begin{tabular}{|c|} 
Enterobacter \\
spp. \\
$\mathrm{n}=6$
\end{tabular} & $\begin{array}{c}\text { Citrobacter } \\
\text { spp. } \\
\mathrm{n}=2\end{array}$ & $\begin{array}{c}\text { S. aureus } \\
\mathrm{n}=7\end{array}$ & $\begin{array}{c}\text { CoNS } \\
n=1\end{array}$ \\
\hline Ampicillin (AMP) & NT & $\begin{array}{c}11 \\
(100 \%)\end{array}$ & NT & NT & NT & NT & NT & NT \\
\hline Ciprofloxacin (CIP) & $\begin{array}{c}10 \\
(33.33 \%)\end{array}$ & $\begin{array}{c}7 \\
(63.64 \%)\end{array}$ & $\begin{array}{c}5 \\
(31.25 \%)\end{array}$ & $\begin{array}{c}4 \\
(57.4 \%)\end{array}$ & $\begin{array}{c}3 \\
(50 \%)\end{array}$ & $\begin{array}{c}1 \\
(50 \%)\end{array}$ & $\begin{array}{c}2 \\
(28.57 \%)\end{array}$ & $\begin{array}{c}0 \\
(0.00 \%)\end{array}$ \\
\hline Cotrimoxazole (COT) & $\begin{array}{c}20 \\
(66.67 \%)\end{array}$ & $\begin{array}{c}7 \\
(63.64 \%)\end{array}$ & $\begin{array}{c}9 \\
(56.25 \%)\end{array}$ & $\begin{array}{c}6 \\
(85.7 \%)\end{array}$ & $\begin{array}{c}5 \\
(83.33 \%)\end{array}$ & $\begin{array}{c}1 \\
(50 \%)\end{array}$ & $\begin{array}{c}2 \\
(28.57 \%)\end{array}$ & $\begin{array}{c}0 \\
(0.00 \%)\end{array}$ \\
\hline $\begin{array}{l}\text { Piperacillin } \\
\text { /tazobactum (PIT) }\end{array}$ & $\begin{array}{c}6 \\
(20 \%)\end{array}$ & $\begin{array}{c}0 \\
(0.00 \%)\end{array}$ & $\begin{array}{c}0 \\
(0.00 \%)\end{array}$ & $\begin{array}{c}2 \\
(28.57 \%)\end{array}$ & $\begin{array}{c}0 \\
(0.00 \%)\end{array}$ & $\begin{array}{c}0 \\
(0.00 \%)\end{array}$ & NT & NT \\
\hline Amikacin (AK) & $\begin{array}{c}13 \\
(43.33 \%)\end{array}$ & $\begin{array}{c}7 \\
(63.64 \%)\end{array}$ & $\begin{array}{c}5 \\
(31.25 \%)\end{array}$ & $\begin{array}{c}6 \\
(85.7 \%)\end{array}$ & $\begin{array}{c}5 \\
(83.33 \%)\end{array}$ & $\begin{array}{c}1 \\
(50 \%)\end{array}$ & $\begin{array}{c}1 \\
(14.29 \%)\end{array}$ & $\begin{array}{c}0 \\
(0.00 \%)\end{array}$ \\
\hline Gentamicin (GEN) & $\begin{array}{c}17 \\
(56.67 \%)\end{array}$ & $\begin{array}{c}6 \\
(54.55 \%) \\
\end{array}$ & $\begin{array}{c}8 \\
(50 \%)\end{array}$ & $\begin{array}{c}5 \\
(71.43 \%)\end{array}$ & $\begin{array}{c}5 \\
(83.33 \%) \\
\end{array}$ & $\begin{array}{c}1 \\
(50 \%)\end{array}$ & $\begin{array}{c}2 \\
(28.57 \%)\end{array}$ & $\begin{array}{c}0 \\
(0.00 \%)\end{array}$ \\
\hline Cefotaxime (CTX) & $\begin{array}{c}28 \\
(93.33 \%)\end{array}$ & $\begin{array}{c}9 \\
(81.82 \%)\end{array}$ & $\begin{array}{c}15 \\
(93.75 \%)\end{array}$ & $\begin{array}{c}7 \\
(100 \%)\end{array}$ & $\begin{array}{c}6 \\
(100 \%)\end{array}$ & $\begin{array}{c}2 \\
(100 \%)\end{array}$ & $\begin{array}{c}4 \\
(57.14 \%)\end{array}$ & $\begin{array}{c}0 \\
(0.00 \%)\end{array}$ \\
\hline Ceftazidime (CAZ) & $\begin{array}{c}27 \\
(90 \%)\end{array}$ & $\begin{array}{c}10 \\
(90.90 \%)\end{array}$ & $\begin{array}{c}14 \\
(87.5 \%)\end{array}$ & $\begin{array}{c}7 \\
(100 \%)\end{array}$ & $\begin{array}{c}6 \\
(100 \%)\end{array}$ & $\begin{array}{c}2 \\
(100 \%)\end{array}$ & NT & NT \\
\hline Erytromycin (E) & $\begin{array}{c}23 \\
(76.67 \%)\end{array}$ & $\begin{array}{c}8 \\
(72.73 \%)\end{array}$ & $\begin{array}{c}11 \\
(68.75 \%)\end{array}$ & $\begin{array}{c}6 \\
(85.7 \%)\end{array}$ & $\begin{array}{c}4 \\
(66.67 \%) \\
\end{array}$ & $\begin{array}{c}2 \\
(100 \%)\end{array}$ & $\begin{array}{c}2 \\
(28.57 \%)\end{array}$ & $\begin{array}{c}0 \\
(0.00 \%)\end{array}$ \\
\hline Meropenem (MRP) & $\begin{array}{c}0 \\
(0.00 \%)\end{array}$ & $\begin{array}{c}0 \\
(0.00 \%)\end{array}$ & $\begin{array}{c}0 \\
(0.00 \%)\end{array}$ & $\begin{array}{c}0 \\
(0.00 \%)\end{array}$ & $\begin{array}{c}0 \\
(0.00 \%)\end{array}$ & $\begin{array}{c}0 \\
(0.00 \%)\end{array}$ & NT & NT \\
\hline Oxacillin (OX) & NT & NT & NT & NT & NT & NT & $\begin{array}{c}2 \\
(28.57 \%)\end{array}$ & $\begin{array}{c}0 \\
(0.00 \%)\end{array}$ \\
\hline Vancomycin (VA) & NT & NT & NT & NT & NT & NT & $\begin{array}{c}0 \\
(0.00 \%)\end{array}$ & $\begin{array}{c}0 \\
(0.00 \%)\end{array}$ \\
\hline
\end{tabular}


Table 3: Bacteriological profile of Multidrug Resistant (MDR) and Extended Spectrum $\beta$-lactamase (ESBL) producing organisms.

\begin{tabular}{|l|c|c|c|c|}
\multicolumn{1}{|c|}{ Organisms } & Number & $\begin{array}{c}\text { MDR } \\
\text { N (\%) }\end{array}$ & $\begin{array}{c}\text { ESBL-producer } \\
\text { N (\%) }\end{array}$ & p-value \\
\hline E. coli & 11 & $7(63.63)$ & $5(45.45)$ & \\
\hline K. pneumoniae & 30 & $23(76.67)$ & $23(76.67)$ & \\
\hline K. oxytoca & 7 & $4(57.14)$ & $3(42.86)$ & \\
\hline Acinetobacter spp. & 16 & $9(56.25)$ & $9(56.25)$ & 0.001 \\
\hline Enterobacter spp. & 6 & $6(100)$ & $6(100)$ & \\
\hline Citrobacter spp. & 2 & $1(50)$ & $1(50)$ & \\
\hline S. aureus & 7 & $2(28.57)$ & NT & \\
\hline CoNS & 1 & $0(0)$ & NT & \\
\hline Total & $\mathbf{8 0}$ & $\mathbf{5 2}(\mathbf{1 0 0 . 0 )}$ & $\mathbf{4 7 ( 1 0 0 )}$ & \\
\hline
\end{tabular}

K. pneumoniae was resistant to cefotaxime (93.33\%) followed by ceftazidime (90\%) erythromycin (76.67\%) while sensitive to meropenem (100\%). All isolated E.coli were resistant to Ampicillin $(100 \%)$ and followed by ceftazidime $(90 \%)$ and cefotaxime $81.82 \%$ ). Acinetobacter spp. was sensitive to piperacillin/tazobactum and meropenem $(100 \%)$ where as $100 \%$ resistance to cefotaxime and ceftazidime. Remaining other isolated Gram negative bacteria such as $K$. oxytoca, Acinetobacter spp., Citobacter spp. and Enterobacter spp. were $100 \%$ resistance to cefotaxime and ceftazidime while Gram positive bacteria such as $S$. aureus and CoNS were sensitive to Vancomycin (100\%). CoNS were sensitive to all treated antibiotics (Table 2).

Out of total 80 isolated organisms, 52 organisms were found multidrug resistant (MDR). Enterobacter spp. $(100 \%)$ were predominant MDR bacteria followed by K. pneumoniae (76.67\%). The numbers of ESBL-producing bacteria were 47 and among them, Enterobacter spp. (100\%) was predominant ESBL-producing bacteria which were followed by K. pneumoniae (76.67\%). The association between MDR and ESBL-producing organisms were statistically significant $(\mathrm{p}=0.001)$ (Table 3 ).

\section{DISCUSSION}

Although considerable practice in hygiene has been adopted and new antimicrobial agents have been introduced, the most common cause of death among newborns was reported to be neonatal infections like sepsis in both developed and developing countries as well which accounted for $6 \%$ to $25 \% .{ }^{8}$ Thus, it is very crucial to have information on the bacteriological profile and the appropriate antibiotics to treat sepsis in order to overcome mortality and morbidity due to neonatal sepsis. ${ }^{8}$ In the current study, 80 blood culture specimen were found to be positive among 380 blood specimens taken as samples among which the highest proportion with $53.75 \%$ was from males while $46.25 \%$ was from females. This finding of our study is in harmony with the study conducted by Ansari et $\mathrm{al}^{9}$ and Al-Shamahy et al. ${ }^{10}$

The prevalence rate of neonatal sepsis was found to be $21.05 \%$ which is more in comparison to the study conducted by Ansari et al. ${ }^{9}$ The reason for more prevalence of neonatal sepsis in our study is due to differences in geographic location and differences in time during infection as stated by Shrestha et al. ${ }^{11}$ Among total neonatal sepsis, the higher prevalence was found in Early onset of sepsis in comparison to the late onset of sepsis which is in contrast to the finding reported by Yadav et al. ${ }^{12}$ However, this reporting was found to be accord with the reporting done Chaudhary et al. ${ }^{13}$ The highest prevalence of K. pneumonia followed by Acinetobacter spp., E. coli, K.oxytoca, S. aureus, Enterobacter spp., Citrobacter spp., and CoNS was shown by the 
bacterial profile. These species of organisms have been reported as predominant causative agents by numerous studies. ${ }^{11,}{ }^{14}$ The highest proportion of gram-negative isolates was isolated from the study in comparison to the gram-negative isolates which is attributable to the exposure of neonates to a large number of gram-negative bacteria of the vagina. ${ }^{11}$ The most common organism isolated in our study was Klebsiella pneumoniae however, the study performed by Olorukooba et al identified E. coli as the most predominant isolates with $31 \% .{ }^{15}$ Likewise, the study conducted by Onalo et al reported $S$. aureus as a predominant organism with $18 \% .{ }^{16}$ The reason for this different reporting is due to the change in etiology over the years. ${ }^{15}$

In this current study,Meorpenem and Piperacillin/ tazobactam were observed to be the most effective antimicrobial agents against Gram-negative bacteria while Cefotaxime and Ceftazidime were found to be the least effective antimicrobial agents. Similar effectiveness of Meropenem and Piperacillin/ tazobactam was reported to all Gram-negative organisms by a study performed by Shrestha et al., ${ }^{17}$ Desai and Malek., ${ }^{9}$ Ozkan et al. ${ }^{18}$ On the other hand, in the case of Gram-positive bacteria, Vancomycin were found to be the most effective antibiotic in comparison to other antibiotics. A diverse antibioticresistant pattern has been reported in the different studies over different times. The rationale for this is due to the emergence of antibiotic-resistant strains which is due to the irrational use of antimicrobials. ${ }^{9}$

Similarly, of the total of 80 positive isolates, $65 \%$ isolates were found multidrug-resistant (MDR) among which Enterobacter spp. with 100\% were predominant MDR. Those bacteria were considered MDR in this research study if they exhibit the ability to induce resistance to at least one antibiotic from distinct classes of common antimicrobial agents ${ }^{20}$. Moreover, $58.75 \%$ of isolates were found to be ESBL producers of a total of 80 positive isolates which is very high when compared to the finding reported by the study conducted by Dolma et al. ${ }^{21}$ Enterobacter spp. $(100 \%)$ was the most common ESBL-producer in comparison to other isolates which is contrary to the study performed by Zakariya where $K$. pneumoniae was reported to be the predominant ESBL producer with total $54.5 \%{ }^{22}$

\section{Limitation of the study}

In this study, the molecular level study could not be performed due to the unavailability of a molecular lab on the hospital and the sample could not transport to other molecular laboratories for further study from the hospital due to the stringent rules and regulations of that hospital. Furthermore, the further characterization of CoNS could not be performed up to species level.

\section{CONCLUSIONS}

To conclude, the bacterial pathogens were isolated from $21.05 \%$ specimens which indicate the prevalence rate of neonatal sepsis to be $21.05 \%$ of which, the higher prevalence was found in the early onset of sepsis. The predominant organism that was responsible for causing neonatal sepsis was found to be $K$. pneumoniae. Meropenem and Piperacillin/tazobactam were observed to be the most effective antimicrobial agents against Gramnegative bacteria while Vancomycin was found to be the most effective antibiotic in the case of Grampositive bacteria. The prevalence of MDR and ESBL among bacteria in sepsis suspected neonates in this study was very high with $65 \%$ and $54.5 \%$ respectively. The significant rise in MDR and ESBL in sepsis suspected neonates can be mitigated by making the rational choice of antibiotics and by identifying appropriate strategies to minimize the infection. Neonatal sepsis is difficult to identify and can be asymptomatic. So, laboratory testing with blood culture should be done immediately. If sepsis is suspected clinically, empirical treatment with appropriate antibiotics which is guided by the AST pattern of common bacteria in NICU must be started. Moreover, clinical and epidemiological investigations are necessary to assess changes in the organisms that cause neonatal sepsis. Further 
studies using PCR should be performed including genotypic characterization of organisms involved in neonatal sepsis. Agents with high intrinsic activity against Enterobacter spp. should be selected for severely ill patients. Rapid diagnostic tests are highly needed in our country to detect ESBL-producing bacteria from neonate's blood in order to reduce the mortality with ESBL-producing bacterial neonatal sepsis.

\section{ACKNOWLEDGEMENT}

We would like to acknowledge the microbiology department of Paropakar Maternity and Women's Hospital for allowing us to perform research and to collect data from the laboratory.

\section{Conflict of Interest: None}

\section{NJHS}

\section{REFERENCES}

1. Heron M. Deaths. Leading Causes for 2011.2015 July 27 [cited 2019 Jan 15]; 64(7):1-95. Available from: https://pubmed.ncbi.nlm.nih.gov/26222685/ PMID: 26222685

2. Singh M, Alsaleem M, Gray CP. Neonatal Sepsis. 2021 Mar 3. [cited 2021 May 2] ; Available from: https://www.ncbi.nlm.nih.gov/books/NBK531478/ PMID: 30285373 .

3. Raha, B. K., Baki, M. A., Begum, T., Nahar, N., Jahan, N.,Begum, M. Clinical, Bacteriological Profile \& Outcome of Neonatal Sepsis in a Tertiary Care Hospital. (2014) [cited 2019 Jan 19]; 26(1):18-21. Available from : https://doi.org/10.3329/medtoday.v26i1.21306

4. Aggarwal R, Sarkar N, Deorari AK, Paul VK. Sepsis in the newborn. Indian J Pediatr. 2001 Dec [cited 2019 Jan 18]; 68(12):1143-7. Available from: https:// pubmed.ncbi.nlm.nih.gov/11838570/doi: 10.1007/BF02722932. PMID: 11838570

5. Alemu M, Belete MA, Gebreselassie S, Belay A, Gebretsadik D. Bacterial Profiles and Their Associated Factors of Urinary Tract Infection and Detection of Extended Spectrum Beta-Lactamase Producing Gram-Negative Uropathogens Among Patients with Diabetes Mellitus at Dessie Referral Hospital, Northeastern Ethiopia. Diabetes MetabSyndrObes. 2020 Aug [cited 2021 Sep 3]19(13):2935-2948. Available from: https://pubmed.ncbi.nlm.nih.gov/32922054/doi: 10.2147/ DMSO.S262760. PMID: 32922054; PMCID: PMC7450280.

6. CLSI. Performance Standards for Antimicrobial Susceptibility Testing. 27th Ed. CLSI Supplement M100. Wayne, PA: Clinical and Laboratory Standards Institute; 2017.

7. Mehrad B, Clark NM, Zhanel GG, Lynch JP 3rd. Antimicrobial resistance in hospital-acquired gram-negative bacterial infections. Chest. 2015[cited 2020 March 6];147(5):1413-1421.Available from: https://www.ncbi.nlm.nih.gov/pmc/articles/PMC4420185/ doi:10.1378/chest.14-2171

8. Yadav, N.S., Sharma, S., Chaudhary, D.K.Bacteriological profile of neonatal sepsis and antibiotic susceptibility pattern of isolates admitted at Kanti Children's Hospital, Kathmandu, Nepal. 2018 May 15 [cited 2019 March 28];301:2018 Availble from: https://bmcresnotes.biomedcentral.com/articles/10.1186/s13104018-3394-6\#citeas doi: https://doi.org/10.1186/s13104-018-3394-6

9. Ansari S, Nepal HP, Gautam R, Shrestha S, Neopane P, Chapagain ML. Neonatal septicemia in Nepal: early-onset versus late-onset. International journal of pediatrics. 2015 Nov [cited 2019 March 28];16:2015. Available from: https:/www.hindawi.com/journals/ijpedi/2015/379806/ doi: https://doi.org/10.1155/2015/379806

10. Al-Shamahy HA, Sabrah AA, Al-Robasi AB, Naser SM. Types of Bacteria associated with Neonatal Sepsis in Al-Thawra University Hospital, Sana'a, Yemen, and their Antimicrobial Profile. Sultan QaboosUniv Med J. 2012 Feb [cited 2019 March 26];12(1):48-54. Available from: https://pubmed.ncbi.nlm.nih. gov/22375258/doi: 10.12816/0003087. PMID: 22375258

11. Shrestha RK, Rai SK, Khanal LK, Manda PK. Bacteriological study of neonatal sepsis and antibiotic susceptibility pattern of isolates in Kathmandu, Nepal.2013 Mar[cited 2020 Feb 21];15(1):71-73.Available from: https://europepmc.org/article/med/24592800 PMID: 24592800.

12. Yadav, N.S., Sharma, S., Chaudhary, D.K. Bacteriological profile of neonatal sepsis and antibiotic susceptibility pattern of isolates admitted at Kanti Children's Hospital, Kathmandu, Nepal 2018 May 3[cited 2020 April 15];301:2018 Available from: https://bmcresnotes.biomedcentral.com/articles/10.1186/s13104-0183394-6\#citeas doi:https://doi.org/10.1186/s13104-018-3394-6

13. ChoudhuryHabiburRasul, M. Abul Hassan , M. Habibullah. Neonatal Sepsis And Use Of Antibiotic In A Tertiary Care Hospital.2007 [cited 2020 April 15]; 23(1):78-81 Available from: https://pjms.com.pk/issues/janmar07/pdf/neonatal_sepsis.pdf

14. Shaw CK, Shaw P, Thapalial A. Neonatal sepsis bacterial isolates and antibiotic susceptibility patterns at a NICU in a tertiary care hospital in western Nepal: a retrospective analysis. Kathmandu Univ Med J (KUMJ). 2007 Apr-Jun[cited 2019 March 11];5(2):153-60. Available from: https://pubmed.ncbi.nlm.nih. gov/18604011/ PMID: 18604011.

15. Olorukooba AA, Ifusemu WR, Ibrahim MS, Jibril MB, Amadu L, Lawal BB. Prevalence and Factors Associated with Neonatal Sepsis in a Tertiary Hospital, North West Nigeria. Niger Med J. 2020[cited 2021 Sep 10];61(2):60-66.Available from: https://www.ncbi.nlm.nih.gov/pmc/articles/PMC7357807/ doi:10.4103/ nmj.NMJ_31_19

16. Onalo R, Ogala WN, Ogunrinde GO, Olayinka AT, Adama SA, Ega BA. Predisposing factors to neonatal septicaemia at ahmadubello university teaching hospital, zaria Nigeria. Niger Postgrad Med J. 2011 Mar[cited 2021 Sep 9];18(1):20-5.Available from: https://pubmed.ncbi.nlm.nih.gov/21445109/ PMID: 21445109.

17. Shrestha S, Lama L, Sharma A, Gs S (2015). Neonatal Sepsis :Bacteriological Profile and Antibiotic Sensitivity Pattern in Nepal. Nepal Med Coll 17: $43-46$.

18. Ozkan H, Cetinkaya M, Koksal N, Celebi S, Hacımustafaoglu M. Culture-proven neonatal sepsis in preterm infants in a neonatal intensive care unit over a 7 year period: coagulase-negative Staphylococcus as the predominant pathogen. Pediatr Int. 2014 Feb;56(1):60-6.Available from:https://pubmed.ncbi.nlm.nih. gov/24003995/doi: 10.1111/ped.12218. PMID: 24003995 . 
19. Dolma K, Summerlin TL, Wongprasert H, Lal CV, Philips Iii JB, Winter L. Early-Onset Neonatal Sepsis with Extended Spectrum Beta-Lactamase Producing Escherichia Coli in Infants Born to South and South East Asian Immigrants: A Case Series. AJP Rep. 2018[cited 2021 Sep 13];8(4):e277-e279. Available from: https://www.ncbi.nlm.nih.gov/pmc/articles/PMC6205855 doi:10.1055/s-0038-1675336

20. Daynia E. Ballot, Trusha Nana, Charlotte Sriruttan, Peter A. Cooper. Bacterial Bloodstream Infections in Neonates in a Developing Country.2012 Aug [2020 Dec 01];2012(508512):6.Available from: https://www.hindawi.com/journals/isrn/2012/508512/ doi:https://doi.org/10.5402/2012/508512

21. Ahmed AS, Chowdhury MA, Hoque M, Darmstadt GL. Clinical and bacteriological profile of neonatal septicemia in a tertiary level pediatric hospital in Bangladesh. Indian Pediatr.2002 Nov [cited 2019 Jan 20]; 39(11):1034-9.Available from: https://pubmed.ncbi.nlm.nih.gov/12466574/ PMID: 12466574.

22. Patel SJ, Saiman L. Antibiotic resistance in neonatal intensive care unit pathogens: mechanisms, clinical impact, and prevention including antibiotic stewardship. ClinPerinatol. 2010 Sep [cited 2019 Jan 15]; 37(3):547-63. Available from:https://pubmed.ncbi.nlm.nih.gov/20813270/doi: 10.1016/j.clp.2010.06.004. PMID: 20813270; PMCID: PMC4440667.

23. Bhattacharjee A, Sen MR, Prakash P, Gaur A, Anupurba S. Increased prevalence of extended spectrum beta lactamase producers in neonatal septicaemic cases at a tertiary referral hospital. Indian J Med Microbiol. 2008 Oct-Dec[cited 2019 Feb 3]; 26(4):356-60. Available from:https://pubmed.ncbi.nlm.nih.gov/18974490/ doi: 10.4103/0255-0857.43578. PMID: 18974490 . 